\title{
Auxílio Emergencial em Tempos de Pandemia: uma estratégia além da vida
}

\author{
Juliana Vitória Vieira M. da Silval, Almir Rodrigues Durigon², Rubens dos Santos ${ }^{3}$, \\ Aldo César da Silva Ortiz, Tatiane Rosa Carvalho Ribeiro ${ }^{5}$, Enézio Mariano da Costa ${ }^{6}$
}

\begin{abstract}
Resumo: $O$ objetivo do estudo foi assessorar os empreendedores individuais, trabalhadores informais, autônomos, desempregado que estavam com dúvidas na solicitação do auxílio emergencial instituído pela Lei 13.982/2020. A metodologia adotada para assessorar os participantes foi a ferramenta digital do Whatsapp,para manter o distanciamento social e recomendado pela Organização Mundial da Saúde - OMS. O projeto foi divulgado nas redes sociais da Universidade do Estado de Mato Grosso e em grupos de Whatsapp. Foram atendidas 254 pessoas em um período de 40 dias. Os principais atendimentos foram os esclarecimentos de como preencher o cadastro; auxílio no acesso do aplicativo "Caixa Tem"; solicitação do benefício; auxílio na criação da conta digital e regularização do Cadastro de Pessoa Física - CPF. Conclui-se que o auxílio emergencial é uma medida de caráter essencial para a manutenção da dignidade da população brasileira, principalmente nesse momento de crise estabelecido pela pandemia do COVID 19.
\end{abstract}

Palavras-chave: Auxílio emergencial. Covid. Whatsapp.

Área Temática: Políticas Públicas.

\section{Emergency aid in pandemic times: a strategy beyond life}

Abstract: The objective of the study was to advise individual entrepreneurs, informal workers, self-employed, unemployed who were in doubt when requesting emergency assistance instituted by Law 13,982 / 2020. The methodology adopted to assist participants was the digital Whatsapp tool, to maintain social distance and recommended by the World Health Organization - WHO. The project was publicized on the social networks of the State University of Mato Grosso and in Whatsapp groups. 254 people were served in a period of 40 days. The main assistance was clarification on how to fill out the registration form; assistance in accessing the "Caixa Tem" application; benefit request; assistance in the creation of the digital account and regularization of the Individual Taxpayer Registration - CPF. It is concluded that emergency aid is an essential measure for maintaining the dignity of the Brazilian population, especially in this moment of crisis established by the pandemic of COVID 19.

Keywords: Emergency aid. Covid. Whatsapp.

\section{Ayuda de emergencia en tiempos de pandemia: una estrategia más allá de la vida}

Resumen: El objetivo del estudio fue asesorar a empresarios individuales, trabajadores informales, autónomos, desempleados que tuvieran dudas al solicitar la asistencia de emergencia instituida por la Ley 13.982 / 2020. La

\footnotetext{
${ }^{1}$ Contadora, Doutora em Administração, Professora da UNEMAT, Cáceres-MT, Brasil, E-mail: julianamattiello@unemat.br;

${ }^{2}$ Contador, Doutor em Ciências Contábeis, Professor da UNEMAT, Cáceres-MT, Brasil, E-mail:almir@unemat.br;

${ }^{3}$ Contador, Doutor em Ciências Políticas pela UERJ, Professor da UNEMAT, Cáceres-MT, Brasil, E-mail: rubens@ unemat.br;

${ }^{4}$ Contador, Mestre em Ciências Contábeis pela UNISINOS, Professor da UNEMAT, Cáceres-MT, Brasil, E-mail: aldo@ unemat.br;

${ }^{5}$ Contadora, Mestre em Educação pela UNEMAT, Professora da UNEMAT, Cáceres-MT, Brasil: e-mail: tatiana.ribeiro@ unemat.br;

${ }^{6}$ Contador, Mestre em Administração, Professor da UNEMAT, Cáceres-MT, Brasil, E-mail: eneziocon@ gmail.com.
} 
metodología adoptada para asistir a los participantes fue la herramienta digital de Whatsapp, para mantener la distancia social y recomendada por la Organización Mundial de la Salud - OMS, el proyecto fue divulgado en las redes sociales de la Universidad Estatal de Mato Grosso y en grupos de Whatsapp. Se atendió a 254 personas en un período de 40 días. La principal ayuda fue la aclaración sobre cómo completar el formulario de registro; asistencia en el acceso a la aplicación "Caixa Tem"; solicitud de beneficios; asistencia en la creación de la cuenta digital y regularización del Registro de Contribuyentes Personales - CPF. Se concluye que la ayuda de emergencia es una medida esencial para mantener la dignidad de la población brasileña, especialmente en este momento de crisis establecido por la pandemia de COVID 19.

Palabras clave: Ayuda de emergencia. COVID-19. Whatsapp.

\section{INTRODUÇÃO}

A pandemia é a "disseminação mundial de uma nova doença e o termo passa a ser usado quando uma epidemia, surto que afeta uma região, se espalha por diferentes continentes com transmissão sustentada de pessoa para pessoa" (Schueler, 2020 p.1). Após a divulgação da pandemia, no Brasil, muitas atividades foram suspensas, inclusive o fechamento das atividades de ensino.

Após a suspensão, algumas medidas por parte do Governo Federal foram instituídas, dentre elas, temos a Lei 13.982/2020, que institui o crédito extraordinário para pagamento do auxílio emergencial para trabalhadores informais, desempregados, empreendedores individuais.

Auxílio Emergencial é o benefício financeiro concedido pelo Governo Federal destinado aos trabalhadores informais, microempreendedores individuais (MEI), autônomos e desempregados, e tem por objetivo fornecer proteção emergencial no período de enfrentamento à crise causada pela pandemia do Coronavírus - COVID 19. (CAIXA ECONÔMICA FEDERAL, 2020).

Após a promulgação da Lei 13.982/2020, um número elevado de pessoas buscou meios para a solicitação do auxílio emergencial. Com isso, possíveis beneficiários amparados pela referida lei esbarraram em diversos obstáculos, tais como fraudes, falhas e inconsistências de sistema, além de dificuldades para realizar a solicitação por não possuírem aparelho de celular, não terem acesso à internet ou apresentarem dificuldade para preencher o cadastro.

Essa situação gerou aglomerações nas portas dos bancos, em especial, da Caixa Econômica Federal, "as aglomerações nos bancos tiveram início quando foi divulgada a informação de que os solicitantes do auxílio que tivessem qualquer pendência em seus CPFs não poderiam receber o dinheiro" (Brasil Econômico, 2020, p. 1).

Nesta direção, o artigo traz um relato de experiência da implantação do auxílio emergencial, do assessoramento aos empreendedores individuais, trabalhadores informais, autônomos, desempregados, todos que estavam com dúvidas no processo de solicitação do benefício instituído pela Lei 13.982/2020.

O uso da tecnologia de informação e comunicação - TIC, possibilitou atender as medidas restritivas e de distanciamento social para implantar o Auxilio Emergencial. 


\section{METODOLOGIA}

O projeto foi desenvolvido por meio de ferramentas digitais, na modalidade EAD, em respeito ao distanciamento social estabelecido pelo governo Federal, Estadual e Municipal. A principal plataforma adotada para a equipe de professores e alunos que estavam na execução do projeto foi o Whatsapp. Tal ferramenta foi usada para a troca de ideias entre a equipe do projeto, bem como para eventuais reuniões (no caso, duas) pelo Google Meet, com a intenção de discutir alguns pontos a fim de compreender todos os aspectos relativos à Lei 13.982/2020, que trata especificamente de todas as regras para concessão do auxílio emergencial.

Após a compreensão da legalidade a respeito do auxílio emergencial e ajuste entre a equipe de trabalho, foi elaborado um folder para divulgação digital do atendimento on-line. $\mathrm{O}$ folder (Figura 1) contou com a colaboração e assessoria de mídias da UNEMAT. Para a construção do folder, dividimos: em equipes, para melhor atender a população, com atendimento no período matutino das $8 \mathrm{~h}$ às $11 \mathrm{~h}$ com 05 membros do projeto, contanto com professores e acadêmicos do curso de ciências contábeis e mais 05 dividido nesse mesmo formato para o período vespertino com atendimento das $13 \mathrm{~h}$ às $16 \mathrm{~h}$. Os números de telefones eram dos próprios membros do projeto.

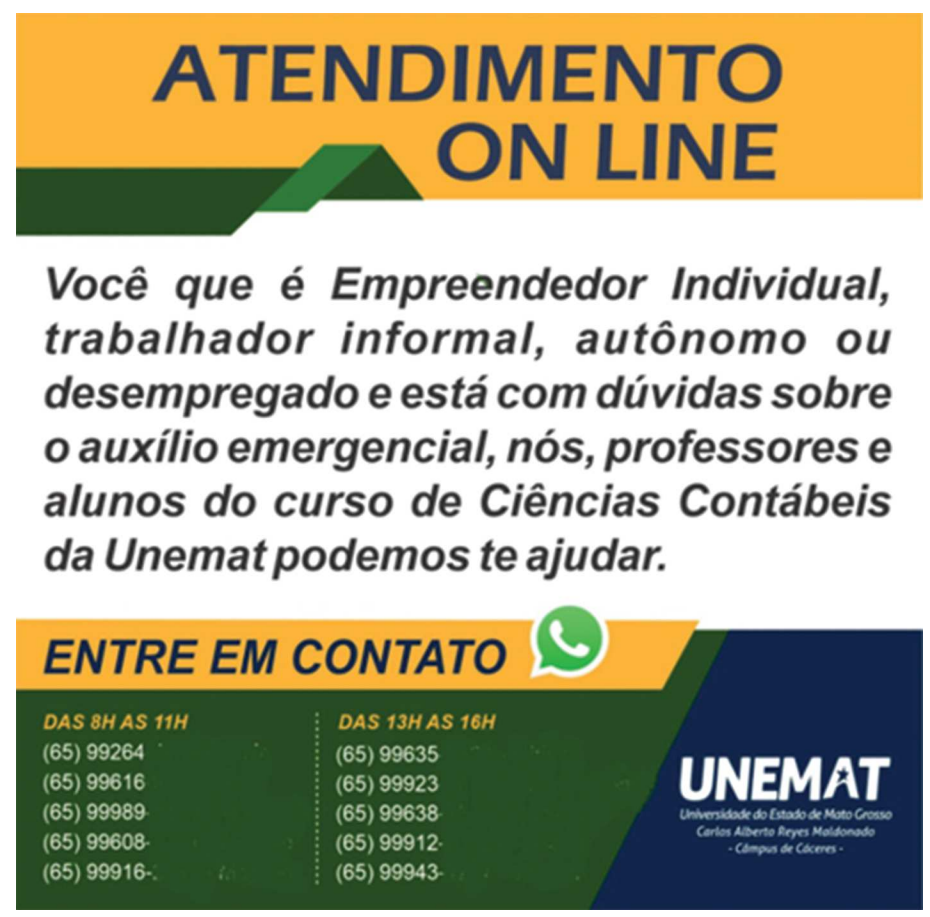

Figura 1: Folder para divulgação dos atendimentos. Fonte: Dados do projeto.

O folder foi divulgado nas mídias sociais da Unemat e nas mídias particulares dos integrantes do projeto. Após a divulgação, iniciaram os atendimentos por meio de ligações telefônicas e também atendimento via Whatsapp. O projeto teve início no dia 14 de abril de 2020 e finalizou no dia 31 de maio de 2020. Foram atendidas 254 pessoas no período em vigência. 
Mesmo após a compreensão da legalidade do auxílio surgiram dúvidas por parte da equipe acerca do aplicativo "caixa tem" e sobre atendimento na caixa. Apesar disso, as dúvidas eram prontamente esclarecidas no grupo criado no Whatsapp. Houve muita interação e troca de experiência nos atendimentos.

\section{RESULTADO E DISCUSSÃO}

\section{DOS ATENDIMENTOS}

O total de atendimentos realizados foi de 254 pessoas. As principais solicitações foram: (ver quadro 1)

Quadro 1: Tipo de Atendimento

\begin{tabular}{|l|}
\hline \multicolumn{1}{|c|}{ TIPO DO ATENDIMENTO } \\
\hline - Auxílio no cadastro \\
\hline - Ajuda para Contestar o benefício negado \\
\hline - Dúvidas quando o CPF acusava estar irregular \\
\hline - Dúvidas pelo recebimento através do Bolsa Família \\
\hline - Auxílio na criação da conta no "Caixa Tem” \\
\hline - Dúvidas sobre o Cad-Único \\
\hline Fonte: Dados do projeto (2020)
\end{tabular}

Por meio de nosso projeto, pelo número de cadastrados, foi possível encontrar um total de 145 pessoas que tiveram o cadastro aprovado para o recebimento do auxílio. No entanto, acredita-se que esse número pode ser um pouco maior, pois a equipe percebeu que as pessoas demonstraram receio de passar o número do CPF. Dessa maneira, não foi possível consultar se todos os atendimentos tiveram o benefício aprovado, pois sem o número do CPF não havia como consultar.

Além dos números alcançados no projeto, percebeu-se o quanto foi importante para os participantes da equipe estarem na execução desta proposta, pois o sentimento de ajudar o próximo é indescritível. Em um cenário um tanto delicado, provocado por uma pandemia, o fato de estar disponível e tentar ajudar os menos favorecidos propiciou aos participantes a oportunidade de experimentar situação de "ajudar as pessoas" e ganhar reconhecimento com sentimento de "gratidão" pelos beneficiários. Em seguida, apresenta-se a descrição enviada por áudio de uma pessoa que foi atendida pelo projeto:

Oi ....... tudo bem? Graças a Deus consegui receber a $1^{\mathrm{a}}$ parcela tanto do meu tio quanto da minha tia, tá? E eu quero só agradecer a você e dizer que graças a você foi possível dar essa ajuda pra eles e saiba que você fez um bem muito grande para pessoas que realmente precisavam e pode ter certeza que esses seiscentos reais vai significar um pedacinho de carne na mesa deles, um par de chinelo, uma conta de luz e água que eles vão pagar, um remédio porque eles são pessoas muito humildes, tá? Que Deus abençoe você e te de muita, muita, muita saúde, Obrigada por tudo o que você fez e eles estão muito felizes, tá? tchau e muito obrigada, qualquer dúvida eu volto a te perturbar (risos). 
Com esse áudio, constatou-se o sentimento de gratidão dos atendidos pelo projeto e por parte dos integrantes da equipe. De forma especial, a pessoa que fez esse atendimento mencionado teve a oportunidade de fazer o bem sem olhar a quem, simplesmente, ouvir uma mensagem de voz cheia de gratidão e contentamentoé impagável. Como ela disse: "estou extremamente feliz e agradecida pela oportunidade que vocês estão nos dando de poder ajudar as pessoas e fazer o bem".

\section{CONCLUSÕES}

O Objetivo do projeto foi de assessorar os empreendedores individuais, trabalhadores informais, autônomos, desempregado que estavam com dúvidas na solicitação do auxílio emergencial instituído pela Lei $13.982 / 2020$.

A equipe do projeto atendeu a 254 pessoas através de ligações telefônicas e pela plataforma do Whatsapp, onde foi prestado assessoria quanto ao cadastro do auxílio emergencial, Cad-Único, contestação de benefícios recusados, regularização de CPF, esclarecimentos em relação ao bolsa família e auxílio emergencial e criação de conta no "Caixa Tem".

Como resultado desse projeto, averiguou-se o valor social que as universidades desempenham em qualquer situação, principalmente em um momento de pandemia. O ensino propicia a evolução social, desenvolve a cognição e o conhecimento.

Conclui-se que as medidas de apoio são indispensáveis para a assistência da dignidade da população brasileira, e por esta razão, é fundamental que o poder público não apenas mantenha, mas amplie o Auxilio Emergencial, bem como conceba outras formas de políticas públicas para ajudar a população a passar por esse período de crise sanitária e econômica.

Em assim sendo, o que fica dessa experiência é o sentimento de "gratidão" de todos os envolvidos com o projeto. A possibilidade de poder ajudar gera um contentamento impagável e desenvolve habilidades sociais dos alunos e professores que na maioria das vezes não são aprendidas em sala de aula e que a extensão é capaz de proporcionar. Sugere-se que novos projetos possam ser desenvolvidos para atender aos menos esclarecidos para ajudar, fortalecer e desenvolver o Estado de Mato Grosso.

\section{REFERÊNCIAS}

BRASIL. Lei 13.982/2020 de 02 de abril de 2020. Institui o auxílio emergencial. Disponível em: <http:// www.planalto.gov.br/ccivil_03/_ato2019-2022/2020/lei/113982.htm>. Acesso em 14 Abr. 2020.

\section{BRASIL ECONÔMICO. Espera, falhas e filas em agências: a "batalha" para receber auxílio no}

Brasil. IG, 29/04/2020. Disponível em: <https://economia.ig.com.br/2020-04-29/espera-falhas-e-filas-emagencias-a-batalha-para-receber-auxilio-no-brasil.html >. Acesso em: 31 Ago. 2020 
CAIXAECONÔMICAFEDERAL.Auxílio Emergencial. 2020. Disponível em: <http://www.caixa.gov.br/ auxilio/PAGINAS/DEFAULT2.ASPX>. Acesso em 31 Ago. 2020.

SCHUELER, Paulo. O que é uma pandemia. Fiocruz, 23 de março de 2020. Disponível em: <https:// www.bio.fiocruz.br/index.php/br/noticias/1763-o-que-e-uma-pandemia>. Acesso: em 31 Ago. 2020.

Submetido em: 17/03/2021 Aceito em: 07/05/2021. 